\title{
Technical note: Droplet digital PCR as a new molecular method for a simple and reliable diagnosis of freemartinism in cattle
}

\author{
I. Szczerbal, ${ }^{1}$ J. Nowacka-Woszuk, ${ }^{1}$ S. Albarella, ${ }^{2}$ and M. Switonski ${ }^{1 *}$ \\ ${ }^{1}$ Department of Genetics and Animal Breeding, Poznan University of Life Sciences, Wołynska 33, 60-637, Poznan, Poland \\ ${ }^{2}$ Department of Veterinary Medicine and Animal Production, University of Naples Federico II, via Delpino 1, Naples 80137, Italy
}

\section{ABSTRACT}

Freemartinism is the most common type of disorder of sex development in cattle. It leads to sterility in the female co-twin in heterosexual twin pregnancy, and is thus a serious problem in cattle production. The incidence of freemartin syndrome is directly dependent on the prevalence of twinning, which has increased in dairy cattle populations in recent years. Thus, early and rapid identification of freemartins is needed to reduce economic loss. Of the various methods used to diagnose this condition, identifying the $\mathrm{XX}$ and $\mathrm{XY}$ cell lines in blood samples using cytogenetic techniques is the gold standard; however, this technique is time consuming. Faster and more reliable techniques are thus being sought. Droplet digital PCR (ddPCR) is a third-generation PCR method and it has not previously been used to detect $\mathrm{XX} / \mathrm{XY}$ leukocyte chimerism in cattle. The aim of the present study was to verify the usefulness of ddPCR to detect and quantify leukocyte chimerism in this species. The $\mathrm{X}$ and $\mathrm{Y}$ copy numbers were estimated by identifying the copy numbers of 2 genes located on the sex chromosomes: amelogenin Xlinked $(A M E L X)$ on the $\mathrm{X}$ chromosome and amelogenin Y-linked $(A M E L Y)$ on the Y chromosome. In the first step, we performed ddPCR on samples prepared from female DNA mixed with male DNA in serially diluted proportions. We determined that the sensitivity of this method was sufficient to detect a low-frequency $(<5 \%)$ cell line. In the next step, ddPCR was used to analyze 22 Holstein Friesian freemartins. Cytogenetic evaluation of these cases revealed leukocyte chimerism; the proportion of XX and XY metaphase spreads varied over a wide range, from XX $(98 \%) / \mathrm{XY}(2 \%)$ to $\mathrm{XX}$ $(4 \%) / X Y(96 \%)$. The use of ddPCR facilitated the precise estimation of the ratio of the copy number of $\mathrm{X}$ to $\mathrm{Y}$ sex chromosomes. In all cases, the XX/XY chimerism

Received May 25, 2019.

Accepted June 28, 2019.

*Corresponding author: switonsk@up.poznan.pl detected by cytogenetic analysis was confirmed using ddPCR. The method turned out to be very simple, accurate, and sensitive. In conclusion, we recommend the ddPCR method for fast and reliable detection of XX/ $\mathrm{XY}$ leukocyte chimerism in cattle.

Key words: amelogenin gene, disorder of sex development (DSD), freemartinism, intersexuality, sex chromosomes

\section{Technical Note}

Freemartinism is a well-known type of disorder of sex development in cattle (Komisarek and Dorynek, 2002; Peretti et al., 2008; Villagómez et al., 2009). It is observed in heifers born of heterosexual twin pregnancies and results in an underdeveloped reproductive system, masculinization, and sterility. The condition is caused by the development of vascular anastomoses between the placentas of the heterosexual twin fetuses, leading to migration into the female fetus of the maleness factors responsible for the differentiation of the embryonic gonads into testicles. The effect of heterosexual twin pregnancy on the male individual is uncertain; however, decreased fertility has occasionally been reported in such animals (Padula, 2005; Kozubska-Sobocinska et al., 2016). Interestingly, this syndrome is also observed in single-born heifers from heterosexual twin pregnancies where the male fetuses died during pregnancy (Szczerbal et al., 2014a). It is estimated that anastomoses develop in up to $97 \%$ of bovine twin pregnancies (Esteves et al., 2012). The occurrence of twinning in Holstein Friesian cattle is about 5\% but can reach $10 \%$ or more in some herds (Andreu-Vázquez et al., 2012; Lett and Kirkpatrick, 2018). The twinning rate has increased over time and the trend is likely to continue (Mur-Novales et al., 2018). As a consequence, the incidence of freemartinism is also expected to increase.

A tentative diagnosis of freemartinism is based on the clinical examination of reproductive tracts in heifers and on information about the number and sex of calves delivered by a cow. Confirmation of this diagnosis requires genetic investigation, with the aim of deter- 
mining the presence of 2 blood cell lines that differ in sex chromosome complement: XX (the heifer's cell line) and XY (the male co-twin's cell line). The presence of both lines is referred to as $\mathrm{XX} / \mathrm{XY}$ leukocyte chimerism. Several cytogenetic and molecular techniques are used for this purpose, but chromosome analysis is the most common approach. Cytogenetic identification of bovine sex chromosome can be done using conventional Giemsa staining, chromosome banding techniques, or the FISH (fluorescence in situ hybridization) technique with sex-chromosome probes (Rubes et al., 2009; Kozubska-Sobocinska et al., 2016). In contrast, molecular techniques rely on detecting Y-linked genes through a standard PCR, real-time quantitative (q)PCR, or genotyping of sex chromosome-linked microsatellite markers (Ron et al., 2011; Qiu et al., 2018). Cytogenetic analysis allows the proportion of XX and XY cells to be precisely determined; however, the approach is time consuming and labor intensive. The entire procedure involves the sterile collection of a blood sample, which must then be rapidly transported (within about $24 \mathrm{~h}$ ) to a diagnostic laboratory; a leukocyte cell culture is then established (48 or $72 \mathrm{~h}$ ), and microscopic slides are prepared and analyzed by specialized staff. The standard PCR approach to detect Y-linked genes is easier but does not distinguish between $\mathrm{XX} / \mathrm{XY}$ chimerism with a low proportion of the XX cell line and the XY form of disorder of sex development, which is also observed in cattle (De Lorenzi et al., 2018). The approach thus needs additional molecular studies, such as analysis of microsatellite markers in other tissues (e.g., hair follicles, saliva; Szczerbal et al., 2014b).

Droplet digital PCR (ddPCR) is a third-generation PCR that offers new possibilities for detecting XX/XY chimerism. This method was developed to overcome the limitations of conventional amplification techniques in detecting low-abundance nucleic acids. It allows precise quantification of target nucleic acids in a sample by using absolute measurements (Pinheiro et al., 2012). Compared with other quantitative PCR that use rate-based measurements (cycle threshold values) and require the use of calibration curves, ddPCR is a direct method of quantification. It has been found useful in determining the genetic profiles of forensic mixtures and clinical chimerism in human patients (George et al., 2013; Stahl et al., 2016; Santurtún et al., 2017; Kliman et al., 2018).

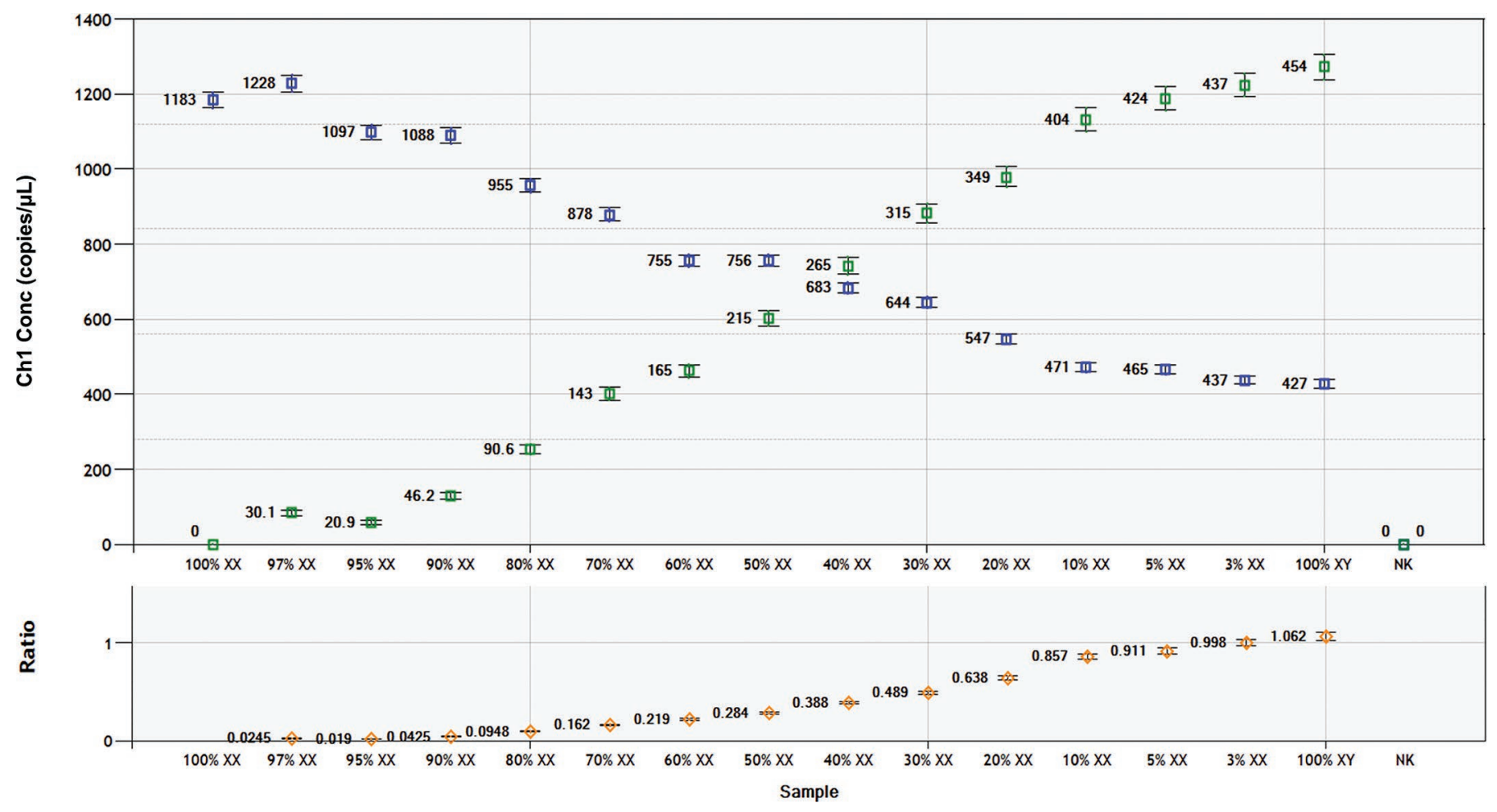

Figure 1. Estimation of $A M E L X$ (blue) and $A M E L Y$ (green) gene copy numbers by droplet digital PCR (ddPCR) in samples prepared from female DNA mixed with male DNA in serially diluted proportions. Data are shown as concentration $($ copies $/ \mu \mathrm{L})$ and $\mathrm{Y} / \mathrm{X}$ ratio. NK $=$ negative control (no DNA template). Error bars represent the 95\% CI. 


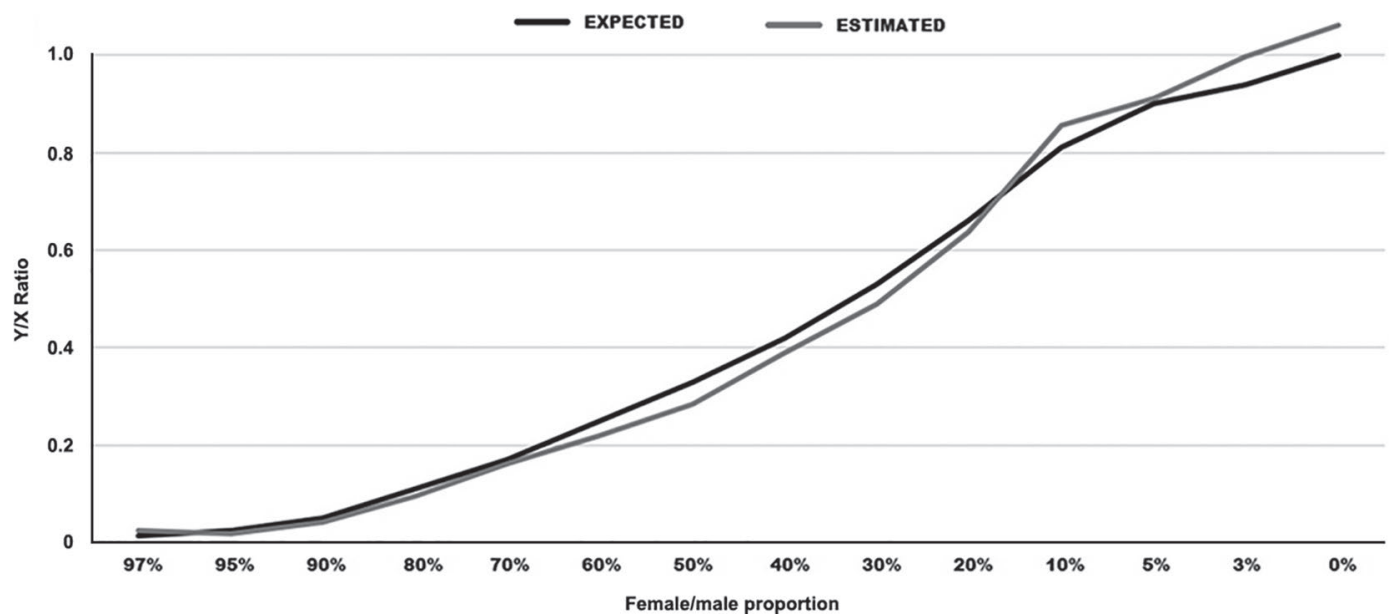

Figure 2. Expected and observed Y/X ratios in samples prepared from female/male mixed DNA in serially diluted proportions.

So far, the technique has been used to detect leukocyte chimerism only in pigs (Szczerbal et al., 2019). Because freemartin syndrome is an important problem in cattle

Table 1. Comparison of cytogenetic analysis and the droplet digital PCR (ddPCR) method in detecting chimeric status in Holstein Friesian freemartins ${ }^{1}$

\begin{tabular}{|c|c|c|c|c|c|c|}
\hline \multirow[b]{2}{*}{$\begin{array}{l}\text { Animal } \\
\text { ID }\end{array}$} & \multicolumn{3}{|c|}{ Cytogenetic analysis } & \multicolumn{3}{|c|}{ ddPCR } \\
\hline & $\begin{array}{l}\mathrm{XX} \\
(\%)\end{array}$ & $\begin{array}{l}\mathrm{XY} \\
(\%)\end{array}$ & $\begin{array}{l}\mathrm{Y} / \mathrm{X} \\
\text { ratio }\end{array}$ & $\begin{array}{c}A M E L X \\
(\text { copies } / \mu \mathrm{L})\end{array}$ & $\begin{array}{c}A M E L Y \\
(\text { copies } / \mu \mathrm{L})\end{array}$ & $\begin{array}{l}\mathrm{Y} / \mathrm{X} \\
\text { ratio }\end{array}$ \\
\hline $23^{2}$ & 100 & 0 & - & 1,501 & 0 & - \\
\hline 17 & 98 & 2 & 0.01 & 1,332 & 125 & 0.094 \\
\hline 18 & 98 & 2 & 0.01 & 4,200 & 139 & 0.033 \\
\hline 12 & 93 & 7 & 0.03 & 191 & 20 & 0.1 \\
\hline 7 & 92 & 8 & 0.04 & 193 & 10 & 0.05 \\
\hline 22 & 81 & 19 & 0.1 & 3,110 & 351 & 0.11 \\
\hline 14 & 80 & 20 & 0.11 & 189 & 24 & 0.13 \\
\hline 15 & 74 & 26 & 0.15 & 1,047 & 330 & 0.31 \\
\hline 13 & 66 & 34 & 0.20 & 208 & 60 & 0.29 \\
\hline 1 & 64 & 36 & 0.22 & 254 & 68 & 0.27 \\
\hline 8 & 64 & 36 & 0.22 & 198 & 82 & 0.41 \\
\hline 2 & 63 & 37 & 0.23 & 107 & 41 & 0.39 \\
\hline 6 & 58 & 42 & 0.26 & 115 & 66 & 0.57 \\
\hline 11 & 54 & 46 & 0.30 & 199 & 26 & 0.13 \\
\hline 3 & 53 & 47 & 0.30 & 104 & 50 & 0.49 \\
\hline 19 & 50 & 50 & 0.33 & 560 & 155 & 0.28 \\
\hline 5 & 48 & 52 & 0.35 & 141 & 96 & 0.69 \\
\hline 4 & 47 & 53 & 0.36 & 169 & 41 & 0.24 \\
\hline 10 & 46 & 54 & 0.36 & 141 & 79 & 0.56 \\
\hline 20 & 30 & 70 & 0.53 & 427 & 223 & 0.52 \\
\hline 16 & 22 & 78 & 0.63 & 114 & 74 & 0.65 \\
\hline 9 & 6 & 94 & 0.88 & 1,825 & 1,183 & 0.64 \\
\hline 21 & 4 & 96 & 0.92 & 977 & 856 & 0.87 \\
\hline $24^{3}$ & 0 & 100 & 1 & 150 & 151 & 1 \\
\hline
\end{tabular}

${ }^{1}$ The percentage of XX and XY cell lines was estimated using an evaluation of 50 to 100 metaphase spreads. The $\mathrm{X}$ and $\mathrm{Y}$ chromosome copy numbers were estimated by ddPCR by quantifying the AMELX/ $A M E L Y$ genes. The results are shown as $\mathrm{Y} / \mathrm{X}$ ratios.

${ }^{2}$ Control female $(60, \mathrm{XX})$.

${ }^{3}$ Control male $(60, \mathrm{XY})$. breeding, we wanted to use this method to rapidly diagnose XX/XY leukocyte chimerism, which is closely associated with freemartinism.

To estimate the copy numbers of $\mathrm{X}$ and $\mathrm{Y}$ chromosomes, we designed 2 ddPCR assays specific to the bovine $A M E L X$ and AMELY genes. The same set of primers was used to amplify fragments of both genes, whereas the probes were specific to each gene. Primer sequences were as follows: forward (F): 5'-CCAGCCACCTGTGC-3'; reverse (R): 5'-GGCTGCATGGGGAATA-3'; and probe sequences were (AMELX) 5-'CAGCGCTTGCCACC FAM_IowaBlack-3' and (AMELY) 5'-CAGCCCTTGCCGC HEX_IowaBlack-3'. Genomic DNA from blood samples was isolated using commercial kits; and DNA concentrations and quality were measured using a NanoDrop Spectrophotometer (Thermo Fisher Scientific, Waltham, MA) and a Qubit Fluorometer (Thermo Fisher Scientific). Approximately $20 \mathrm{ng}$ of DNA was used per ddPCR reaction. The reaction mixture contained $10 \mu \mathrm{L}$ of $2 \times$ ddPCR Supermix for Probes (Bio-Rad, Hercules, CA), $1 \mu \mathrm{L}$ of $20 \times$ primers/ FAM probe, $1 \mu \mathrm{L}$ of $20 \times$ primers/HEX probe $(900 \mathrm{n} M$ primers and $250 \mathrm{n} M$ probes), and $1 \mu \mathrm{L}$ of $B s u \mathrm{I}$ restriction enzyme (diluted 1:2). The PCR reaction mixtures were partitioned into approximately 20,000 droplets using a QX200 droplet generator (Bio-Rad). The PCR was performed on a Gradient T100 Thermal Cycler (Bio-Rad) using thermal cycle conditions as follows: denaturation at $95^{\circ} \mathrm{C}$ for $10 \mathrm{~min} ; 40$ cycles at $94^{\circ} \mathrm{C}$ for $30 \mathrm{~s}$ and $55^{\circ} \mathrm{C}$ for $60 \mathrm{~s}\left(\operatorname{ramp}\right.$ rate $\left.2^{\circ} \mathrm{C} / \mathrm{s}\right) ; 98^{\circ} \mathrm{C}$ for 10 min, and $10^{\circ} \mathrm{C}$ until reading time. The droplets were analyzed on a QX200 droplet reader (Bio-Rad). The concentration of AMELX and AMELY genes was calculated using the Poisson distribution with Quantasoft software (Bio-Rad). 


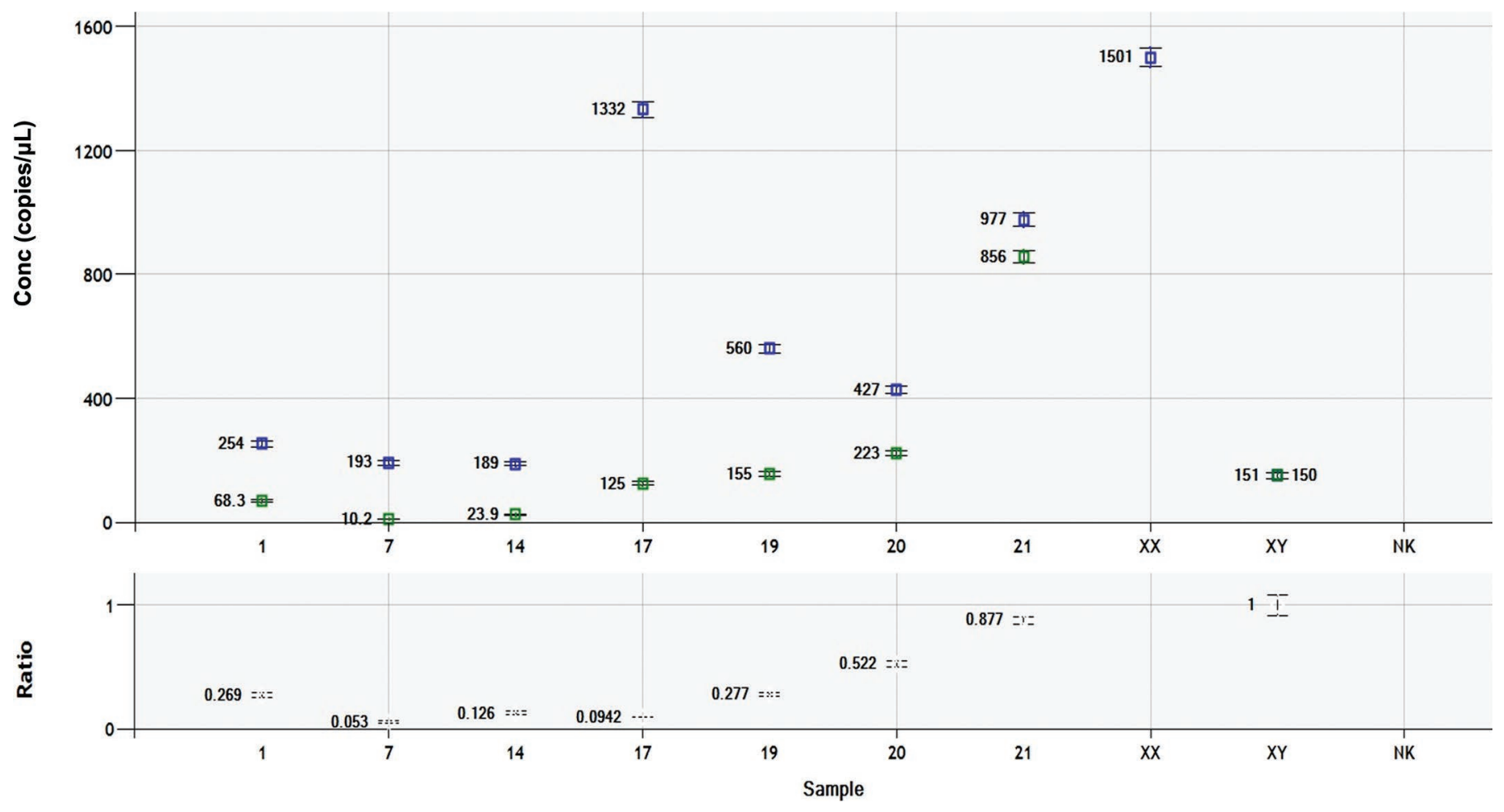

Figure 3. Examples of droplet digital PCR (ddPCR) analysis on samples from freemartin cases (numbers as in Table 1) based on the ratio of $\mathrm{X}$ to $\mathrm{Y}$ chromosomes based on estimation of copy numbers of the AMELX (blue) and AMELY (green) genes. Data are shown as concentrations $($ copies $/ \mu \mathrm{L})$ and $\mathrm{Y} / \mathrm{X}$ ratios. NK = negative control (no DNA template). Error bars represent the $95 \%$ CI.

To evaluate the specificity of ddPCR, we tested artificial samples prepared from a control female DNA (XX) mixed with a control male DNA (XY) in serially diluted proportions (see Supplemental Table S1; https: //doi.org/10.3168/jds.2019-17021). In the next step, ddPCR was used to analyze samples derived from freemartins $(\mathrm{n}=22)$, which we had previously diagnosed cytogenetically in our laboratories. Blood samples were collected by veterinarians following standard veterinary protocols. For each individual, cytogenetic preparations were obtained from in vitro leukocyte cultures and sex chromosomes were identified using Giemsa staining based on their bi-armed morphology (Supplemental Figure S1; https://doi.org/10.3168/jds.2019-17021). The proportion of XX and XY cell lines was estimated by microscopic analysis of at least 50 metaphase spreads.

The ddPCR performed on the serially diluted bovine male and female DNA mixed samples provided precise quantification of $\mathrm{X}$ and $\mathrm{Y}$ chromosome copy numbers (Figure 1). The XX/XY ratio determined by ddPCR was in agreement with the expected values (Figure 2, Supplemental Table S1; https://doi.org/10 .3168/jds.2019-17021). Small discrepancies were noted between the measured and expected ratios in samples with $3 \%$ and $5 \%$ XY cell lines; however, the differ- ences were very small and irrelevant in the assessment of chimeric status. The method was sensitive enough to detect the 2 cell lines even when they occurred at low frequency $(3 \%)$. The next step of the analysis was conducted on samples from freemartins. Cytogenetic evaluation revealed that the ratio of $\mathrm{XX}$ and $\mathrm{XY}$ cell lines varied from XX (98\%)/XY (2\%) to XX (4\%)/XY $(96 \%)$ (Table 1). The ddPCR analysis confirmed the chimeric status in all cases (Figure 3), and the $\mathrm{Y} / \mathrm{X}$ ratios estimated by ddPCR were in agreement with the cytogenetic data; Pearson correlation coefficient (r) was 0.87 (Table 1).

As shown herein for the first time, ddPCR facilitates the rapid and reliable detection of $\mathrm{XX} / \mathrm{XY}$ leukocyte chimerism in cattle, including quantitative detection of $\mathrm{X}$ and $\mathrm{Y}$ chromosome copies. This method is also cost effective: we estimate that the cost per sample of ddPCR is approximately one-fourth of the cost of cytogenetic testing. The ddPCR approach can also be used for the detection of whole-body XX/XY chimerism or mosaicism, but additional analysis of samples representing other tissue (e.g., hair follicles) is necessary. Because freemartinism is an emerging problem in dairy herds, and one that leads to economic losses, we recommend the use of ddPCR for routine diagnosis in dairy cattle herds. 


\section{ACKNOWLEDGMENTS}

This study was financed by the statutory fund of the Department of Genetics and Animal Breeding, Poznan University of Life Sciences, Poland (no. 506.534.04.00).

\section{REFERENCES}

Andreu-Vázquez, C., I. Garcia-Ispierto, S. Ganau, P. M. Fricke, and F. López-Gatius. 2012. Effects of twinning on the subsequent reproductive performance and productive lifespan of high-producing dairy cows. Theriogenology 78:2061-2070.

De Lorenzi, L., S. Arrighi, E. Rossi, P. Grignani, C. Previderè, S. Bonacina, F. Cremonesi, and P. Parma. 2018. XY (SRY-positive) ovarian disorder of sex development in cattle. Sex Dev. 12:196-203.

Esteves, A., R. Båge, and R. Payan-Carreira. 2012. Freemartinism in cattle. Pages 99-120 in Ruminants: Anatomy, Behavior and Diseases. R. E. Mendes, ed. Nova Science, New York, NY.

George, D., J. Czech, B. John, M. Yu, and L. J. Jennings. 2013. Detection and quantification of chimerism by droplet digital PCR. Chimerism 4:102-108.

Kliman, D., G. Castellano-Gonzalez, B. Withers, J. Street, E. Tegg, O. Mirochnik, J. Lai, L. Clancy, D. Gottlieb, and E. Blyth. 2018. Ultra-sensitive droplet digital PCR for the assessment of microchimerism in cellular therapies. Biol. Blood Marrow Transplant 24:1069-1078.

Komisarek, J., and Z. Dorynek. 2002. Genetic aspects of twinning in cattle. J. Appl. Genet. 43:55-68.

Kozubska-Sobocinska, A., B. Danielak-Czech, and B. Rejduch. 2016. Cytogenetic and molecular diagnostics of XX/XY chimerism in cattle, sheep, and goats: A review. Ann. Anim. Sci. 16:989-1005.

Lett, B. M., and B. W. Kirkpatrick. 2018. Short communication: Heritability of twinning rate in Holstein cattle. J. Dairy Sci. 101:43074311.

Mur-Novales, R., F. Lopez-Gatius, P. M. Fricke, and V. E. Cabrera. 2018. An economic evaluation of management strategies to mitigate the negative effect of twinning in dairy herds. J. Dairy Sci. 101:8335-8349.

Padula, A. M. 2005. The freemartin syndrome: An update. Anim. Reprod. Sci. 87:93-109.
Peretti, V., F. Ciotola, S. Albarella, O. Paciello, C. Dario, V. Barbieri and L. Iannuzzi. 2008. XX/XY chimerism in cattle: Clinical and cytogenetic studies. Sex Dev. 2:24-30.

Pinheiro, L. B., V. A. Coleman, C. M. Hindson, J. Herrmann, B. J. Hindson, S. Bhat, and K. R. Emslie. 2012. Evaluation of a droplet digital polymerase chain reaction format for DNA copy number quantification. Anal. Chem. 84:1003-1011.

Qiu, Q., T. Shao, Y. He, A. U. Muhammad, B. Cao, and H. Su. 2018 Applying real-time quantitative PCR to diagnosis of freemartin in Holstein cattle by quantifying SRY gene: A comparison experiment. PeerJ 6:e4616.

Ron, M., B. Porat, M. R. Band, and J. I. Weller. 2011. Chimaerism detection in bovine twins, triplets and quadruplets using sex chromosome-linked markers. Anim. Genet. 42:208-211.

Rubes, J., A. Pinton, A. Bonnetgarnier, V. Fillon, P. Musilova, K. Michalova, S. Kubickova, A. Ducos, and M. Yerle. 2009. Fluorescence in situ hybridization applied to domestic animal cytogenetics. $\mathrm{Cy}$ togenet. Genome Res. 126:34-48.

Santurtún, A., J. A. Riancho, J. Arozamena, M. López-Duarte, and M. T. Zarrabeitia. 2017. Indel analysis by droplet digital PCR: A sensitive method for DNA mixture detection and chimerism analysis. Int. J. Legal Med. 131:67-72.

Stahl, T., C. Rothe, M. U. Böhme, A. Kohl, N. Kröger, and B. Fehse. 2016. Digital PCR panel for sensitive hematopoietic chimerism quantification after allogeneic stem cell transplantation. Int. J. Mol. Sci. 17:1515

Szczerbal, I., B. Kociucka, J. Nowacka-Woszuk, Z. Lach, J. M. Jaskowski, and M. Switonski. 2014a. A high incidence of leukocyte chimerism $(60, \mathrm{XX} / 60, \mathrm{XY})$ in single born heifers culled due to underdevelopment of internal reproductive tracts. Czech J. Anim. Sci. 59:445-449.

Szczerbal, I., J. Nowacka-Woszuk, S. Dzimira, A. Matuszczyk, P Iskrzak, and M. Switonski. 2019. Elevated incidence of freemartinism in pigs detected by droplet digital PCR and cytogenetic techniques. Livest. Sci. 219:52-56.

Szczerbal, I.. J. Nowacka-Woszuk, W. Nizanski, S. Salamon, M. Ochota, S. Dzimira, W. Atamaniuk, and M. Switonski. 2014b. A case of leucocyte chimerism $(78, \mathrm{XX} / 78, \mathrm{XY})$ in a dog with a disorder of sexual development. Reprod. Domest. Anim. 49:e31-e34.

Villagómez, D. A., P. Parma, O. Radi, G. M. Di, A. Pinton, L. Iannuzzi, and W. A. King. 2009. Classical and molecular cytogenetics of disorders of sex development in domestic animals. Cytogenet. Genome Res. 126:110-131. 